\title{
Analysis of Waiting Time in Emergency Department of Al-Noor Specialist Hospital, Makkah, Saudi Arabia
}

\author{
Hassan Bukhari, Khaled Albazli, Saud Almaslmani, Ashjan Attiah, Esrraa Bukhary, \\ Fatimah Najjar, Abrar Qari, Nabilah Sulaimani, Abeer Al-Lihyani, Alyaa Alhazmi, \\ Haneen Al-Maghrabi, Omnia Alyasi, Sultan Albarqi, Abdullah Salah Eldin \\ Medical College, Umm Al-Qura University, Makkah, Saudi Arabia \\ Email: $\underline{\text { drhb2000@yahoo.com, bazlikhaled@gmail.com }}$
}

Received 6 September 2014; revised 18 October 2014; accepted 16 November 2014

Copyright (C) 2014 by authors and Scientific Research Publishing Inc.

This work is licensed under the Creative Commons Attribution International License (CC BY). http://creativecommons.org/licenses/by/4.0/

(c) (i) Open Access

\begin{abstract}
Emergency Department (ED) in Alnoor Hospital is considered the pulsating unit in the hospital by facing a daily challenge through a huge exposure to number of patients round between $500-700$ per day in average. With this busy service in ED, our study emerges to measure the quality of provided services to patients in term of measuring the total length of stay time (LOS) in ED and its influencing factors. This is a prospective study aiming to estimate the average time patients spend in ED of Alnoor Hospital during the month of January (2013). In addition, it inspects factors influencing the LOS. The questionnaire which conducted and filled by emergency team over all patients was consisted of the following data: arrival time to ED, initial time of assessment by nurse, initial time of assessment by doctor, time of arrival to specific area, consultation time, arrival time of consulted specialty, time of laboratory investigation, time of radiological investigation, time of final disposition and time of physical disposition. For the 7604 patient visits analyzed, mean ED LOS was 3.02 hour (SD = 5.03 hour). About half of the patients spent less than 59 minutes $(44 \%)$, $32.6 \%$ spent 1 to $3: 59$ hour, $15.2 \%$ spent 4 to $7: 59$ hour, and $8.2 \%$ of the patients spent more than 8 hours. A priceless such study will offer an opportunity to evaluate the recent ED performance and assist to adapt future optimization strategies to improve the quality of services provided to the patient.
\end{abstract}

\section{Keywords}

Length of Stay, Emergency Department, Waiting Time 


\section{Introduction}

Emergency medicine is one of the most heavy service specialties as they see a wide range of cases that arrive on a daily base. No other departments can see the different cases in a typical week. The EDs serve as a safety net for patients without access to general practitioners as well as specialty care, which is more expensive and often difficult to obtain in a non-emergent situation [1]. Hence, the principle of providing a high quality care is an important principle for both patient safety and physician.

Worldwide, the ED is facing a serious problem of overcrowding and prolonged wait time affecting patient satisfaction of the service provided [2] [3]. Several factors have been identified in literatures associated with ED patient satisfaction and prolonged length of stay [4]-[7]. Lengthy waiting time has shown to be the main source of poor ED care satisfaction [8].

Emergency Department (ED) of Alnoor Hospital plays a vital important role in providing health care for millions yearly especially during Alhaj season. For that reason, ED staff face a big challenge to provide an efficient and optimized quality of service. Due to the lack of quality studies and statistics provided in Emergency Department at Alnoor Hospital, this study aim to evaluate the level of clinical quality in term of total waiting time for the entire patient flow process from registration through the discharge process. The study evaluates the total length of stay (LOS) in ED and factors affecting this time mainly: time to initial assessment by physician (door-to-doctor), total waiting time for laboratory results, diagnostic imaging, and consultation arrival.

In emergency department (ED) the time is considered a significant tool to measure the quality as this waiting time can affect the outcomes of patient situation and satisfaction, as well the problem of long waiting time can also indicate a poorly resourced, poorly managed and/or poorly co-ordinated department. By 2004, The National Health Service (NHS) in United Kingdom set a target that no one should wait more than four hours from arrival in the ED to admission, discharge, or transfer. This would reduce average waiting time in EDs to 75 minutes [9]. In this study, the evaluation of waiting time has been conducted among ED patients by adapting the 4 hours target waiting time to evaluate the overall total length of stay time of Alnoor Hospital ED and measuring factors influencing this time.

\section{Methodology}

\subsection{Setting}

This study was conducted at the Emergency Department of Alnoor Specialist Hospital, the main tertiary care center in Makkah, Saudi Arabia. The ED saw over 200,000 patients a year and was staffed by one medical or surgical consultant physician with five general practitioners. Pediatric and obstetric and gynecology emergency rooms were not included. This study received approval from Alnoor Specialist Hospital Board.

\subsection{Data Collection}

Research investigators observed the flow of every single patient and manually recorded the data from all patients who attended the ED between midnight Jan. 1, 2013, and midnight Jan. 31, 2013, a continuous 744-h period of study. Age, gender, registration time, initial triage level, triage assessment time, arrival area, door to nurse time, door to doctor time, medical decision time (discharge vs. admit), time of physical disposition, use of laboratory and/or radiology services, and asking for specialty consultation services were recorded for each patient seen during the study period.

\subsection{Time Intervals}

Two pre-defined time intervals were determined and calculated for each patient. The time intervals were: 1) from entry registration to physician assessment and 2) from ED entry to actual departure from the ED. Admitted patients were not considered to have departed from the ED until they were physically transported out of the ED to the hospital inpatient ward or another patient care facility.

The two main time intervals were determined for each patient based on The Canadian Triage \& Acuity Scale level [9] (CTAS I, CTAS II, CTAS III, CTAS IV, CTAS V) and arrival area (Trauma, resuscitation, observation, and triage). 


\subsection{Data Analysis}

Data were recorded on standard study forms and then entered into an SPSS spreadsheet (SPSS 21). Patient demographics, triage levels, arrival area, time intervals and several variable relationships were described using descriptive statistics. Multivariate analysis and multiple linear regression analysis were performed to determine how various patient characteristics and ED service processes influenced LOS. These factors included the following: Laboratory time, patients admission to observation, patients admission to trauma, final decision time to time of physical response to the final decision, consultation time, critical care management patients, door to final decision time, radiology time, non critical care management patients, triage cases, patients admission to resuscitation room, doctor to consultation time, doctor to radiology time, doctor to laboratory time, and door to doctor time. The regression model had LOS in hours as a dependent variable and several independent variables were used for the model. These included initial triage level, arrival area, time to initial assessment by physician, use of laboratory tests, use of diagnostic imaging (X-ray, CT or ultrasound), and specialty service consultation. SPSS statistical software (SPSS version 21) was used to perform the regression analyses.

\section{Result}

During the 31-day study period, 10,226 patients registered in the ED. Of these, 2533 patient charts (24.8\%) were excluded from analysis because of incomplete documentation of total LOS and $89(0.9 \%)$ were excluded because the patient left without being seen.

The mean age of study patients was 37.93 years (standard deviation [SD] $=22.88 \mathrm{yr}$ ) and 58.3\% were male. Among all visits, 93.58\% fell into triage levels III, IV and V. For the 7604 patient visits analyzed, mean ED LOS was 3:02 hour ( $S D=$ 5:03 hour). Table 1 shows the number of visits based on trauma, arrival area, and CTAS level.

CTAS has five acuity levels to V consisting of resuscitation, emergent, urgent, less urgent and non urgent [10]. Patients in triage level I had the shortest LOS, while those in level IV had the longest. About half of the patients spent less than 59 minutes (44\%), 32.6\% spent 1 to 3:59 hour, $15.2 \%$ spent 4 to 7:59 hour, and $8.2 \%$ of the patients spent more than 8 hours.

Time delays increased in the lower triage levels. Registration-to-doctor interval ranged had a mean of 0:19 $\min (\mathrm{SD}=0: 46)$. Table 2 shows the mean and target time of door-to-doctor interval and door-to-door interval for each CTAS level.

Table 1. Number of visits based on trauma, CTAS level, and arrival area.

\begin{tabular}{cccc}
\hline Type of visits & & Number of visits & Percent \\
\hline \multirow{2}{*}{ Trauma } & Yes & 1984 & $25.8 \%$ \\
& Missing & 5286 & $68.7 \%$ \\
\hline \multirow{5}{*}{ CTAS level } & CTAS I & 423 & $5.5 \%$ \\
& CTAS II & 125 & $1.6 \%$ \\
& CTAS III & 112 & $1.5 \%$ \\
& CTAS IV & 278 & $3.6 \%$ \\
& CTAS V & 2302 & $29.9 \%$ \\
& Missing & 909 & $11.8 \%$ \\
Arrival area & Trauma & 3965 & $51.5 \%$ \\
\hline \multirow{5}{*}{} & Observation & 1896 & $24.6 \%$ \\
& Resuscitation & 1470 & $19.1 \%$ \\
& Triage & 281 & $3.7 \%$ \\
& Missing & 1320 & $17.2 \%$ \\
\hline
\end{tabular}


Based on arrival area, the major total LOS time delay was in the observation and trauma areas, while resuscitation and triage had the shortest LOS time (Table 3). Among the total analyzed visits to ED, 4853 patients had a radiological study requests, 4890 laboratory requests, and 4409 consultation requests. As a result of incomplete documentation, there were a great percent of missing requests, $63.40 \%$ radiology requests, $58.28 \%$ laboratory requests, and $77.43 \%$ consultation. Among the requested services in ED, laboratory results had a longer waiting time than radiology results and consultation arrival. $34.13 \%$ of laboratory results had a waiting time more than one hour compared to 4.7 and 4.94 for radiology results and consultation arrival, respectively (Table 4).

Table 2. The mean and target time of door-to-doctor interval and door-to-door interval for each CTAS level.

\begin{tabular}{|c|c|c|c|c|c|}
\hline \multirow{2}{*}{ CTAS } & \multirow{2}{*}{ N (\%) } & \multicolumn{2}{|c|}{ Door to doctor interval } & \multicolumn{2}{|c|}{ Door to door interval } \\
\hline & & $\begin{array}{l}\text { Target door to } \\
\text { doctor time }\end{array}$ & $\begin{array}{l}\text { Observed door to } \\
\text { doctor time }\end{array}$ & $\begin{array}{c}\text { Target total LOS } \\
\text { time }\end{array}$ & $\begin{array}{c}\text { Observed total LOS } \\
\text { time }\end{array}$ \\
\hline CTAS I & $125(1.6 \%)$ & Immediately $98 \%$ of the time & 80.64\% immediately & \multirow{3}{*}{$\begin{array}{c}\text { LOS not to exceed } 6 \\
\text { hours in } 95 \% \text { of } \\
\text { cases }\end{array}$} & \multirow{3}{*}{$\begin{array}{c}\text { LOS did not exceed } 6 \\
\text { hours in } 73.76 \% \text { of } \\
\text { cases }\end{array}$} \\
\hline CTAS II & $112(1.5 \%)$ & $\begin{array}{l}\text { Within } 15 \text { minutes } 95 \% \text { of } \\
\text { the time }\end{array}$ & $70 \%$ within 15 minutes & & \\
\hline CTAS III & $278(3.6 \%)$ & $\begin{array}{c}\text { Within } 30 \text { minutes } 90 \% \text { of } \\
\text { the time }\end{array}$ & $91.50 \%$ within 30 minutes & & \\
\hline CTAS IV & 2302 (29.9\%) & $\begin{array}{l}\text { Within } 60 \text { minutes } 85 \% \text { of } \\
\text { the time }\end{array}$ & $97.84 \%$ within 60 minutes & \multirow{4}{*}{$\begin{array}{l}\text { LOS not to exceed } 4 \\
\text { hours in } 95 \% \text { of } \\
\text { cases }\end{array}$} & \multirow{4}{*}{$\begin{array}{c}\text { LOS did not exceed } 4 \\
\text { hours in } 85.63 \% \text { of } \\
\text { cases }\end{array}$} \\
\hline CTAS V & 909 (11.8\%) & $\begin{array}{l}\text { Within } 120 \text { minutes } 80 \% \text { of } \\
\text { the time }\end{array}$ & 97.88\% within 120 minutes & & \\
\hline latoT & $3726(48.5 \%)$ & & & & \\
\hline gnissiM $^{\mathrm{a}}$ & 3805 (49.5\%) & & & & \\
\hline
\end{tabular}

CTAS: the Canadian triage and acuity scale; LOS: length of stay; ${ }^{\mathrm{a}}$ Missing documented CTAS level.

Table 3. Length of stay per arrival area.

\begin{tabular}{|c|c|c|}
\hline Area & & \\
\hline \multirow{4}{*}{ Resuscitation } & 59 minutes and less & $55.97 \%$ \\
\hline & 1 to $3: 59$ & $35.44 \%$ \\
\hline & 4 to $7: 59$ & $6.28 \%$ \\
\hline & 8 hours and more & $2.31 \%$ \\
\hline \multirow{4}{*}{ Observation } & Less than 59 min & $8.88 \%$ \\
\hline & 1 to $3: 59$ & $27.12 \%$ \\
\hline & 4 to $7: 59$ & $39.09 \%$ \\
\hline & 8 hours and more & $24.91 \%$ \\
\hline \multirow{4}{*}{ Trauma } & Less than 59 min & $9.42 \%$ \\
\hline & 1 to $3: 59$ & $42.77 \%$ \\
\hline & 4 to $7: 59$ & 21.36 \\
\hline & 8 hours and more & $26.45 \%$ \\
\hline \multirow{4}{*}{ Triage } & Less than 59 min & $55.97 \%$ \\
\hline & 1 to $3: 59$ & $35.44 \%$ \\
\hline & 4 to $7: 59$ & $6.28 \%$ \\
\hline & 8 hours and more & $2.31 \%$ \\
\hline
\end{tabular}


The complete regression model yielded an $\mathrm{R}^{2}$ value of $0.137(\mathrm{~F}=2.577, \mathrm{P}<0.04)$. Multivariate analysis was used to examine the influences of explanatory variables on waiting times of patients. The time of arrival to time of physical discharge (i.e. total LOS) was considered the dependent variable. The results showed that laboratory time, patients admission to observation, patients admission to trauma, final decision time to time of physical response to the final decision, consultation time, and critical care management patients were significantly associated with the waiting time $(\mathrm{P}<0.001)$ (Table 5).

Table 4. Waiting time for selected emergency department services.

\begin{tabular}{|c|c|c|c|}
\hline ED service & Waiting time & Number of patients & Percent \\
\hline \multirow{5}{*}{$\begin{array}{c}\text { Radiology result } \\
\text { Median: 2:20 min } \\
\text { Maximum: 9:32 hour } \\
\text { Std. error mean: } 6: 25 \text { min }\end{array}$} & Less than $30 \mathrm{~min}$ & 1317 & $74.16 \%$ \\
\hline & 31 to $60 \mathrm{~min}$ & 231 & $13 \%$ \\
\hline & 61 to $120 \mathrm{~min}$ & 127 & $7.15 \%$ \\
\hline & More than 2 hour & 101 & $5.69 \%$ \\
\hline & Less than $30 \mathrm{~min}$ & 157 & $7.70 \%$ \\
\hline $\begin{array}{l}\text { Laboratory result } \\
\text { Median: 2:49 min }\end{array}$ & 31 to $60 \mathrm{~min}$ & 214 & $10.49 \%$ \\
\hline \multirow[t]{3}{*}{$\begin{array}{l}\text { Maximum: } 12: 31 \text { hour } \\
\text { Std. error mean: 5:48 min }\end{array}$} & 61 to $120 \mathrm{~min}$ & 777 & $38.09 \%$ \\
\hline & More than 2 hour & 892 & $43.72 \%$ \\
\hline & Less than $30 \mathrm{~min}$ & 572 & $57.49 \%$ \\
\hline $\begin{array}{l}\text { Consultation arrival } \\
\text { Median: } 2: 30 \mathrm{~min}\end{array}$ & 31 to $60 \mathrm{~min}$ & 205 & $20.60 \%$ \\
\hline \multirow[t]{2}{*}{$\begin{array}{l}\text { Maximum: 22:00 hour } \\
\text { Std. error mean: 8:18 min }\end{array}$} & 61 to $120 \mathrm{~min}$ & 131 & $13.17 \%$ \\
\hline & More than 2 hour & 87 & $8.74 \%$ \\
\hline
\end{tabular}

Table 5. Multivariate analysis of factors affecting waiting times in the emergency department, with waiting time as the dependent variable.

\begin{tabular}{|c|c|c|c|}
\hline Reason of delay & Number of cases & (n) $\%$ & P-value \\
\hline Laboratory time & 2040 & (1669) 81.81\% & \multirow{6}{*}{$<0.001$} \\
\hline Patients admission to observation & 1470 & (941) 64\% & \\
\hline Patients admission to trauma & 1896 & (907) $47.81 \%$ & \\
\hline $\begin{array}{l}\text { Final decision time to time of physical } \\
\text { response to the final decision }\end{array}$ & 3726 & (1611) $43.23 \%$ & \\
\hline Consultation time & 995 & (218) $21.91 \%$ & \\
\hline Critical care management patients & 515 & (109) $21.24 \%$ & \\
\hline Door to final decision time & 3726 & (600) $16.11 \%$ & 0.174 \\
\hline Radiology time & 1776 & (228) $12.84 \%$ & 0.253 \\
\hline Non critical care management patients & 2580 & (2417) 9.37 & 0.256 \\
\hline Triage cases & 1320 & (1181) 8.95\% & 0.691 \\
\hline Patients admission to resuscitation room & 281 & (241) $8.59 \%$ & 0.734 \\
\hline Doctor to consultation time & 995 & (841) $8.45 \%$ & 0.845 \\
\hline Doctor to radiology time & 1776 & (865) $4.87 \%$ & 0.858 \\
\hline Doctor to laboratory time & 2040 & (767) $3.76 \%$ & 0.865 \\
\hline Door to doctor time & 3726 & (842) $2.26 \%$ & 0.921 \\
\hline
\end{tabular}




\section{Discussion}

This study shows the utility of analyzing time to identify and quantify factors that prolong ED LOS. The CTAS provides objectives for ED nurse and physician response times, as well as recommended response rates, which refer to the proportion of patients in a given triage level who are assessed within CTAS response time objectives. CTAS reflects that the main operational objective is the waiting time to see a physician. The CTAS time objectives provide useful evaluations for benchmarking, and examination of response rates to patients, providing a useful assessment ED flow process [9].

Our data show that, for the most critically ill or injured patients (level I), nursing and physician response times were rapid, with little variability and that, overall, response rate for physician assessment were typically above $80.64 \%$.

In this study, urgent patients spent the longest time in the ED. Short throughput times for levels IV and V patients are explained by lower investigation and consultation rates. The longer ED lengths of stay in level III may reflect the fact that these patients often have vague clinical presentations (not clearly justifying admission or discharge) and require more prolonged observation, investigation and treatment in the ED. Similar to a previous study in Saudi Arabia at King Faisal Specialist Hospital and Research Center (KFSH-RC), most critically ill patients (level I and II), initial assessment was rapid and LOS was prolonged, which are in line with CTAS objectives. This is expected because these patients required more time and manpower resources for the care and management of their critical condition, thus, contributing to a prolonged LOS in the ED [10].

A previous study in Alnoor Specialist Hospital tried to focus on LOS for admitted patients. Total time in ED in that study was defined as "Time of presentation of patient to ED as mentioned in his ED card until time of receipt of that patient by the inpatient nurse in inpatient ward". During the study period out of total patients 4876 who visited the ED only 355 (7.3\%) were admitted with delay of 238 (67\%) more than two hours. Regarding the duration of stay in the ED 80\% cases were admitted in less than 4 hours, 19.2\% admitted between 4 - 8 hours and only $0.8 \%$ admitted after 8 hours after arrival to the ED, which is close to our LOS for all ED patients. The mean ED length of stay (EDLOS) was 3 hours and 11 minutes, similar to our mean EDLOS 3 hours and 2 minutes [11]. KFSH-RC is another hospital in Saudi Arabia, started to adapt the CTAS system in ED and it's targeted waiting time. A better EDLOS has been achieved with 2.4 hours [12]. Hospital admission rate through KFSH-RC ED was 6.7\%, which is in agreement to Alnoor Specialist Hospital admission rate [11] [12].

Most of the ED visits in our study were in CTAS levels IV and V. This is with the agreement of the fact that the majority of patients who attend EDs in Saudi Arabia have non-urgent problems, resulting in overcrowding, excessive waiting times and delayed care for more acutely ill patients [13]. Several factors have been identified for this finding where the most common reasons for attending the ED were not having a regular healthcare provider, being able to receive care on the same day, and the convenience of and access to medical care 24/7. Most of CTAS IV and V patients believe their conditions were more urgent than their triage nurse rating which reflect an insufficient community awareness of the role of the ED [13].

Our findings showed several potential variables influencing waiting times in the ED. Both admissions to trauma and observation area had a significant impact on total LOS. This may be linked to the laboratory work ups requested which was also associated with prolonged LOS. The significance of consultation time on LOS can be related to patients' characteristics and the consulted specialty. Other factors related the hospital and bed capacity could affect LOS by prolonging the final decision time to time of physical response to the final decision.

The regression analysis showed an estimation of how service processes may affect LOS. An $\mathrm{R}^{2}$ of 0.137 for the regression model indicates that LOS may be affected by other factors not examined explain much of the variability in LOS. Further research is required to determine the impact of predictors like socioeconomic status, comorbidity, residency and referral, ED staffing levels, hospital bed capacity and occupancy rates, and hospital policies for housing admitted patients [6].

\section{Limitations}

A major limitation of this study is that data were gathered manually from handwritten study forms and that the study period was limited to one month, precluding analysis of seasonal variation. Moreover, $24.8 \%$ charts were excluded from analysis because of incomplete documentation of LOS time. As with any observational study, deficits in documentation prevented the accurate capture of data elements for several patient care records. ED information systems can improve the accuracy and reliability of data collection to help decision-making [6]. Another limitation of this analysis is the limited finding of relationships between predictor variables causing a 
prolonged LOS. Several external factors may affect LOS; therefore, a meaningful improvement may involve changing a combination of many factors, the assessment of which may be difficult [6].

With long waiting times for ambulatory patients, a great number of patients left without medical evaluation and were not included in the study. Number of patients left without being seen by a physician should be interpreted in light of existing data on the health consequences faced by patients who leave hospital EDs without treatment [14].

\section{Conclusions}

LOS is an effective marker of ED performance and the quality of triage. Our data suggest that patients presenting to our ED have waiting time that vary according to admission area, triage category, consultation time and laboratory work up.

The mean LOS was 3:02 hour (SD = 5:03 hour). 23.4\% of visits to ED had a delay in LOS more than four hours. Prolonged LOS was associated with prolonged laboratory and consultation time, patient admission to observation or trauma areas, critical care management patients, and prolonged final decision time to time of physical response to the final decision. This data will be the guide in identifying the most important projects in the future to shorten the LOS in ED and to provide services that exceed patient's satisfaction.

\section{Acknowledgements}

The authors wish to thank all the medical students from Umm Al-Qura University who participated in the data collections and entry of the research.

\section{References}

[1] Mehmood, A., et al. (2012) Overcrowded Emergency Departments: A Problem Looking for Solution. Journal Pakistan Medical Association, 62, 529-530.

[2] Horwitz, L.I., et al. (2010) US Emergency Department Performance on Wait Time and Length of Visit. Annals of Emergency Medicine, 55, 133-141. http://dx.doi.org/10.1016/j.annemergmed.2009.07.023

[3] Davis, B., et al. (1995) Factors Affecting ED Length-of-Stay in Surgical Critical Care Patients. American Journal of Emergency Medicine, 13, 495-500. http://dx.doi.org/10.1016/0735-6757(95)90155-8

[4] Krall, S.P., et al. (2014) Hospital Factors Impact Variation in Emergency Department Length of Stay More than Physician Factors. Western Journal of Emergency Medicine, 15, 158-164. http://dx.doi.org/10.5811/westjem.2013.12.6860

[5] Schull, M.J., et al. (2002) Urban Emergency Department Overcrowding: Defining the Problem and Eliminating Misconceptions. Canadian Journal of Emergency Medicine, 4, 76-83.

[6] Yoon, P., et al. (2003) Analysis of Factors Influencing Length of Stay in the Emergency Department. Canadian Journal of Emergency Medicine, 5, 155-161.

[7] Parker, B.T. and Marco, C. (2014) Emergency Department Length of Stay: Accuracy of Patient Estimates. Western Journal of Emergency Medicine, 15, 170-175. http://dx.doi.org/10.5811/westjem.2013.9.15816

[8] Locker, T., et al. (2005) Targets and Moving Goal Posts: Changes in Waiting Times in a UK Emergency Department. Emergency Medicine Journal, 22, 710-714. http://dx.doi.org/10.1136/emj.2004.019042

[9] Beveridge, R., Clarke, B., Janes, L., Savage, N., Thompson, J. and Dodd, G. (1999) Canadian Emergency Department Triage and Acuity Scale: Implementation Guidelines. Canadian Journal of Emergency Medicine, 1, S1-S24.

[10] National Emergency Departments Advisory Group (2014) A Quality Framework and Suite of Quality Measures for the Emergency Department Phase of Acute Patient Care in New Zealand. Ministry of Health, Wellington.

[11] Tashkandy, M.A., et al. (2008) Reasons for Delay in Inpatient Admission at an Emergency Department. Journal of Ayub Medical College Abbottabad, 20, 38-42.

[12] Elkum, N.B., et al. (2011) Canadian Emergency Department Triage and Acuity Scale: Implementation in a Tertiary Care Center in Saudi Arabia. BMC Emergency Medicine, 11, 3. http://dx.doi.org/10.1186/1471-227X-11-3

[13] Alyasin, A. and Douglas, C. (2014) Reasons for Non-Urgent Presentations to the Emergency Department in Saudi Arabia. International Emergency Nursing, 22, 220-225. http://dx.doi.org/10.1016/j.ienj.2014.03.001

[14] Stock, L.M., et al. (1994) Patients Who Leave Emergency Departments without Being Seen by a Physician: Magnitude of the Problem in Los Angeles County. Annals of Emergency Medicine, 23, 294-298.

http://dx.doi.org/10.1016/S0196-0644(94)70043-5 
Scientific Research Publishing (SCIRP) is one of the largest Open Access journal publishers. It is currently publishing more than 200 open access, online, peer-reviewed journals covering a wide range of academic disciplines. SCIRP serves the worldwide academic communities and contributes to the progress and application of science with its publication.

Other selected journals from SCIRP are listed as below. Submit your manuscript to us via either submit@scirp.org or Online Submission Portal.
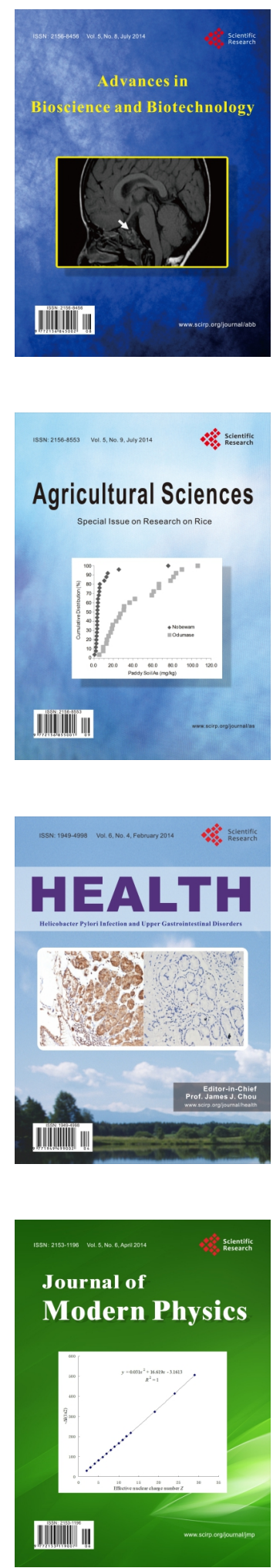
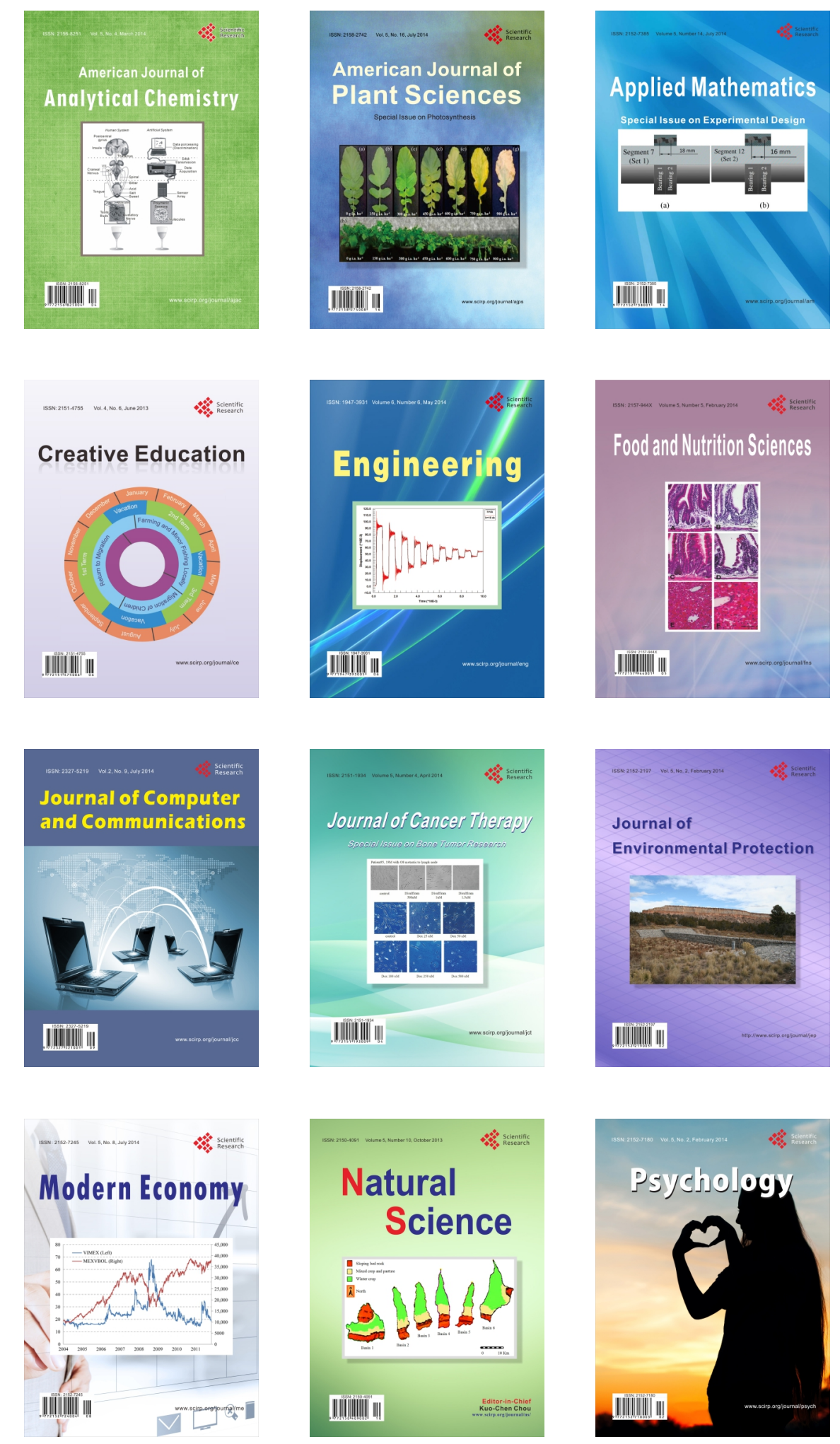